\title{
Metabolic Syndrome in Early Chronic Obstructive Pulmonary Disease: Gender Differences and Impact on Exacerbation and Medical Costs
}

This article was published in the following Dove Press journal: International Journal of Chronic Obstructive Pulmonary Disease

\author{
Hye Sook Choi $\mathbb{1}^{1}$ \\ Chin Kook Rhee (DiD ${ }^{2}$ \\ Yong Bum Park (D) ${ }^{3,4}$ \\ Kwang $\mathrm{Ha}$ Yoo $\mathbb{D}^{5}$ \\ Seong Yong $\operatorname{Lim} \mathbb{1}^{6}$ \\ 'Division of Pulmonary, Allergy, and \\ Critical Care Medicine, Department of \\ Internal Medicine, Kyung Hee Medical \\ Center, Seoul, South Korea; ${ }^{2}$ Division of \\ Pulmonary, Allergy and Critical Care \\ Medicine, Department of Internal \\ Medicine, Seoul St. Mary's Hospital, \\ Seoul, South Korea; ${ }^{3}$ Lung Research \\ Institute of Hallym University College of \\ Medicine, Chuncheon, South Korea; \\ ${ }^{4}$ Division of Pulmonary, Allergy and \\ Critical Care Medicine, Department of \\ Internal Medicine, Hallym University \\ Kangdong Sacred Heart Hospital, Seoul, \\ South Korea; ${ }^{5}$ Division of Pulmonary, \\ Allergy and Critical Care Medicine, \\ Department of Internal Medicine, \\ Konkuk University Medical Center, Seoul, \\ South Korea; ${ }^{6}$ Division of Pulmonary and \\ Critical Care Medicine, Department of \\ Medicine, Kangbuk Samsung Hospital, \\ Sungkyunkwan University School of \\ Medicine, Seoul, South Korea
}

Correspondence: Seong Yong Lim Division of Pulmonary and Critical Care Medicine, Department of Medicine, Kangbuk Samsung Hospital, Sungkyunkwan University School of Medicine, 29, Saemunan-ro, Jongno-gu, Seoul 06652, South Korea

Tel +82-2-200I-2493

Fax +82-2-200I-1596

Email mdlimsy@skku.edu
Background: Metabolic syndrome (MetS) is a well-known comorbidity of chronic obstructive pulmonary disease (COPD). However, their interrelationship, particularly in early COPD, remains unclear. Therefore, we aimed to assess the prevalence and clinical characteristics of MetS in patients with early COPD, and to explore the impact of MetS on the frequency of COPD exacerbations and associated medical costs.

Patients and methods: We retrospectively enrolled 43,874 subjects from the KNHANES, including 2164 patients with early COPD ( $\geq 40$ years old), recorded smoking history, and Global Initiative for Chronic Obstructive Lung Disease spirometric grade I or II, with data linked to the NHI database. We extracted and analyzed data regarding health-care utilization and medical costs for 5 years (2007 to 2012).

Results: Among 2164 patients with early COPD, the prevalence of MetS was $31.2 \%$, and it was higher in women than in men $(35.1 \%$ vs. $26.6 \%$; $\mathrm{P}<0.001)$. Patients with MetS were older and had lower pulmonary function and greater number of comorbidities. The frequency of moderateto-severe COPD exacerbations for 5 years was significantly higher in women with MetS than in those without MetS (5.8/year vs. 4.9/year; $\mathrm{P}=0.02$ ). After adjusting for confounding factors, the risk for moderate-to-severe exacerbation was significantly greater in women with MetS (IRR, $1.17 ; 95 \% \mathrm{CI}, 1.01$ to $1.36 ; \mathrm{P}=0.03$ ). $\mathrm{COPD}$ exacerbations leading to hospitalization and medical expenses were also higher in women with MetS than in those without MetS.

Conclusion: MetS is more prevalent in women with early COPD. MetS increased the frequency of exacerbations and the medical costs in women with early COPD.

Keywords: COPD exacerbation, metabolic syndrome

\section{Plain Language Summary}

Metabolic syndrome is a comorbidity of COPD and increases medical costs. Does metabolic syndrome increase the acute exacerbations of early COPD? Interrelationships between metabolic syndrome and early COPD remain unclear. This paper presents the first analysis that metabolic syndrome increases the acute exacerbations and medical costs in patients with early COPD, especially in women.

\section{Introduction}

Chronic obstructive pulmonary disease (COPD) is characterized by airway inflammation, alveolar destruction, and airflow limitation. ${ }^{1}$ Peripheral lung inflammation may cause the "spill-over" of inflammatory markers into the systemic circulation, leading to extrapulmonary comorbidities such as cardiovascular disease (CVD), 
musculoskeletal wasting, osteoporosis, psychological disorders, and metabolic syndrome (MetS). ${ }^{2,3}$ Alternatively, smoking causes systemic inflammation and COPD, and genetic susceptibility or inflammatory response may have a link to triggers between systemic inflammation and COPD. ${ }^{2,3}$ Thus, COPD is considered a pulmonary component of multiple morbidities. ${ }^{1-3}$ Previous studies have shown that these comorbidities, especially CVD, diabetes, and MetS, are associated not only with a higher risk of hospitalization and mortality ${ }^{4}$ but also with the increased economic burden of COPD. ${ }^{5,6}$ The management of patients with COPD must include the identification and treatment of its comorbidities, ${ }^{1}$ as these have a significant impact on COPD prognosis. ${ }^{1}$

MetS is characterized by the clustering of central obesity, hypertension, dyslipidemia, and hyperglycemia that predisposes patients to CVD. ${ }^{7}$ It is a representative group of conditions with systemic inflammation, which is a potential mechanism responsible for both COPD and MetS. ${ }^{2,3}$ The prevalence of MetS differs according to the sex, race, and agegroup in the general population. ${ }^{8}$ The Global Initiative for Chronic Obstructive Lung Disease (GOLD) report of 2017 stated that the prevalence of MetS in COPD was estimated to be more than $30 \%,{ }^{1}$ and that MetS was more frequent in patients with COPD than in controls. ${ }^{9}$ Moreover, a previous systematic review reported sex differences, showing that patients with COPD and MetS were more frequently women. ${ }^{9}$ The prevalence of MetS is also higher in early (mildto-moderate stage) $\mathrm{COPD}^{10}$ and decreases with COPD progression. $^{10,11}$ Most patients with COPD have early COPD, and their prognosis can be easily improved if they are provided early treatment.

Despite this crucial relationship, studies on MetS in COPD, particularly early COPD, are limited. A few studies reported that MetS increases the frequency of acute exacerbations. ${ }^{11,12}$ However, these studies either included patients with COPD admitted for exacerbations at a single center ${ }^{11}$ or reported preliminary results. ${ }^{12}$ Therefore, we aimed to investigate the prevalence of MetS in early COPD, to determine the relationship between MetS and the frequency of exacerbations in early COPD, and to assess the impact of MetS on COPD-related costs by using data from a national survey.

\section{Materials and Methods}

\section{Study Design and Patients}

This was a retrospective observational study. Data were obtained from the Korean National Health and Nutrition
Examination Survey (KNHANES) (2007 to 2012) database.

The KNHANES was a cross-sectional observational national study conducted by the Ministry of Health and Welfare of Korea in 2007. The KNHANES used a complex and stratified multistage cluster sampling to select a representative nationwide sample of the Korean population. Eligible patients were selected from the KNHANES database and were linked to the National Health Insurance (NHI) database. The researchers were blinded to the personal identity of all patients and they were provided only the merged data lacking any personal identification information.

The NHI database was analyzed to obtain the medical utilization and cost data of patients with early COPD selected from the KNHANES. For outpatients, the analysis was confined to visits with the International Classification of Diseases, Tenth Edition (ICD-10) codes for COPD (J42. X-J44.x, except J43.0) with a prescription of COPD-related medication. For inpatients, the analysis was confined to the ICD-10 codes for COPD (J42.X-J44.X, except J43.0) or COPD-related disease (pneumonia: J12.X-J17.x; dyspnea: R06.0; pulmonary thromboembolism: I26 or I26.0; or acute respiratory distress syndrome: J80) as from our previous studies. Moderate exacerbation of COPD was defined as medical utilization for the above ICD-10 codes and with a prescription for antibiotics or systemic corticosteroids. Severe exacerbation of COPD was defined as an emergency room visit or hospitalization for the above ICD-10 codes and with a prescription for antibiotics or systemic corticosteroids. For the patients with COPD enrolled to the KNHANES in 2007 (baseline), the outcome of exacerbation was prospectively assessed until 2012 for 5 years (follow-up), and for those enrolled to the KNHANES in 2012, the outcome of severe exacerbation was retrospectively assessed to 2007 (baseline) for 5 years (follow-up).

\section{Patients}

Patients with early COPD were selected from the KNHANES (2007 to 2012) database. All the subjects over 20 years old in KNAHNS performed spirometry. The inclusion criteria were 1) age $\geq 40$ years; 2) forced expiratory volume in 1 second $\left(\mathrm{FEV}_{1}\right)$ /forced vital capacity $(\mathrm{FVC})<0.7$; 3) $\mathrm{FEV}_{1} \geq 50 \%$; and 4) a recorded smoking history. They had no history of COPD or asthma diagnosis before study enrollment. MetS in patients with early COPD was defined on the basis of the National Cholesterol Education Program Adult Treatment Panel III, $^{7}$ and we used ethnicity-specific values for waist circumference based on data from the Korean Society for the 
Study of Obesity (KOSSO). ${ }^{13}$ MetS was defined on the basis of the presence of $\geq 3$ of the following factors: ${ }^{7}$ abdominal circumference $>90 \mathrm{~cm}$ for men and $>85 \mathrm{~cm}$ for women based on the KOSSO cutoff points; ${ }^{14}$ elevated triglyceride (TG) level $(\geq 1.7 \mathrm{mmol} / \mathrm{L}$, or drug treatment for elevated TG levels); reduced high-density lipoprotein cholesterol (HDL-C) level $(<1.0 \mathrm{mmol} / \mathrm{L}$ for men or $<1.3$ $\mathrm{mmol} / \mathrm{L}$ for women, or drug treatment for reduced HDLC); elevated blood pressure $(\geq 130 \mathrm{mmHg}$ systolic or $\geq 85$ $\mathrm{mmHg}$ diastolic, or antihypertensive drug treatment for patients with a history of hypertension); and an elevated fasting plasma glucose concentration $(\geq 5.6 \mathrm{mmol} / \mathrm{L}$, or drug treatment for diabetes). ${ }^{7}$

\section{Data Collection}

We obtained information such as age, sex, smoking history (in number of pack-years), blood pressure, body mass index (BMI), abdominal circumference, glucose level, lung function, and laboratory data (TG and HDL-C) from the KNHANES database. Information on comorbidities, history of exacerbation, and COPD-related medical costs were obtained by linking the KNHANES database to the NHI database. Comorbidities were identified using the ICD-10 codes. The codes for hypertension were I10-I15; diabetes, E10-E14; ischemic heart disease (IHD), I20-I25; congestive heart failure (CHF), I50; peripheral vascular disease (PVD), I73; osteoporosis, M80-M81; gastroesophageal reflux disease (GERD), K21; and depression, F32-F33.

\section{Data Analysis}

Baseline characteristics were expressed as mean \pm standard deviation for continuous variables and as frequencies (percentages) for categorical variables. Differences between groups were analyzed using the chi-square test for categorical variables and Student's $t$-test for continuous variables. The difference in the prevalence of MetS between the sexes was determined using chi-square tests. The risk of exacerbations between patients with and without MetS was compared using negative binomial regression. The result estimates were expressed using incidence rate ratios (IRRs) with $95 \%$ confidence intervals (CIs). The IRR of Model 1 was adjusted for age, sex, and $\mathrm{FEV}_{1}$, and the RR of Model 2 was adjusted for age, sex, number of packyears smoked, and $\mathrm{FEV}_{1}$. All tests were two-sided, and P-values $<0.05$ were considered statistically significant. All statistical analyses were performed using SAS version 9.2 software (SAS Institute Inc., Cary, NC, USA).

\section{Results}

\section{Prevalence of MetS}

The study flowchart is shown in Figure S1. In total, 2164 patients with early COPD were identified from the KNHANES database. The overall prevalence of MetS in early COPD was $31.2 \%$ (Table 1). The prevalence of MetS tended to increase significantly according to the decrease in the quartile of $\mathrm{FVC} \%$ predicted. The quartile of $\mathrm{FEV}_{1} \%$ predicted showed no significant relationship with MetS (Table 1). The prevalence of MetS components in early COPD was $59.7 \%$ for hypertension, $47.3 \%$ for HDL-C criteria, $39.8 \%$ for TG criteria, $29.8 \%$ for abdominal circumference, and $12.8 \%$ for glycemia (Figure S2).

\section{Characteristics of Patients with Early COPD According to MetS}

The patients' characteristics on the survey data are summarized in Table 1. The patients with MetS were significantly older and more obese than were those without MetS. Number of pack-years smoked was smaller in patients with MetS than in those without MetS. The number of women with COPD and MetS was greater than that of women with COPD but without MetS ( $31.1 \%$ vs. $26.1 \%$; $\mathrm{P}=0.01)$. The most common comorbidity in MetS was hypertension (78.4\%), followed by diabetes (54.5\%), GERD (52.6\%), PVD (32.4\%), and osteoporosis $(23.6 \%)$. The most common comorbidity in patients without MetS was GERD (54.5\%), followed by hypertension (43.6\%), diabetes (27.4\%), PVD (23.9\%), and osteoporosis (20.5\%). FVC liters and \% predicted and $\mathrm{FEV}_{1}$ liters and \% predicted were significantly lower in patients with MetS than in those without MetS (Table 1).

\section{Sex Differences in the Prevalence of MetS in Early COPD}

The prevalence of MetS was $26.7 \%$ in men and $35.1 \%$ in women $(\mathrm{P}<0.001)$ (Table 2). The mean age and BMI were higher in MetS for both men and women (both $\mathrm{P}<0.001$ ) (Table 2). Ages and frequencies of arthritis were significantly higher in women with MetS. Number of pack-years smoked was smaller in women than in men (Table 2).

\section{COPD Exacerbations and MetS}

Differences in moderate-to-severe exacerbations of COPD between patients with and without MetS are shown in Table 3. No differences were observed in the frequencies of moderate-to-severe exacerbations at baseline and follow-up between patients with and without MetS. However, in 
Table I Baseline Characteristics of Patients with Early COPD

\begin{tabular}{|c|c|c|c|c|}
\hline Variable & Total & No MetS & MetS & $P$ value \\
\hline Total & 2164 & $1489(68.8)$ & $675(31.2)$ & \\
\hline Age, years & $64.6 \pm 9.9$ & $63.8 \pm 10.2$ & $66.2 \pm 9.1$ & $<0.001$ \\
\hline Sex, male & $1566(72.4)$ & $1101(73.9)$ & $465(68.9)$ & 0.015 \\
\hline $\mathrm{BMI}, \mathrm{kg} / \mathrm{m}^{2}$ & $23.5 \pm 2.8$ & $22.9 \pm 2.5$ & $25.0 \pm 2.7$ & $<0.001$ \\
\hline $\mathrm{BMI} \geq 25 \mathrm{~kg} / \mathrm{m}^{2}$ & $1549(7 \mid .6)$ & $283(19.0)$ & $332(49.2)$ & $<0.001$ \\
\hline Participants with a smoking history & $1504(69.5)$ & $1055(70.9)$ & $449(66.5)$ & 0.043 \\
\hline Smoking history, pack-years & $21.0 \pm 23.0$ & $21.11 \pm 22.7$ & $21.0 \pm 23.9$ & 0.950 \\
\hline $\mathrm{SBP}, \mathrm{mmHg}$ & $126.8 \pm 17.5$ & $124.4 \pm 17.7$ & $131.5 \pm 15.9$ & $<0.001$ \\
\hline $\mathrm{DBP}, \mathrm{mmHg}$ & $77.4 \pm 10.3$ & $76.3 \pm 1.0$ & $78.9 \pm 11.2$ & $<0.001$ \\
\hline Abdominal circumference, $\mathrm{cm}$ & $84.9 \pm 8.1$ & $82.7 \pm 7.9$ & $89.0 \pm 7.7$ & $<0.001$ \\
\hline $\mathrm{TG}, \mathrm{mg} / \mathrm{dL}$ & $155.5 \pm 36.2$ & $124.6 \pm 36.3$ & $186.5 \pm 36.2$ & $<0.001$ \\
\hline HDL-C, mg/dL & $44.5 \pm 9.95$ & $48.9 \pm 11.1$ & $40.2 \pm 8.8$ & $<0.001$ \\
\hline Glucose, mg/dL & $102.4 \pm 23.5$ & $97.6 \pm 16.0$ & $113.0 \pm 32.4$ & $<0.001$ \\
\hline Diabetes & $776(35.9)$ & $408(27.4)$ & $368(54.5)$ & $<0.001$ \\
\hline Hypertension & $1178(54.4)$ & $649(43.6)$ & $529(78.4)$ & $<0.001$ \\
\hline IHD & $218(10.1)$ & II7 (7.9) & $101(15.0)$ & $<0.001$ \\
\hline $\mathrm{CHF}$ & $120(5.6)$ & $75(5.0)$ & $45(6.7)$ & 0.125 \\
\hline PVD & $575(26.6)$ & $356(23.9)$ & $219(32.4)$ & $<0.001$ \\
\hline Arthritis & $279(12.9)$ & $173(11.6)$ & $106(15.7)$ & 0.009 \\
\hline Osteoporosis & $464(21.4)$ & $305(20.5)$ & $159(23.6)$ & 0.107 \\
\hline GERD & 1167 (53.9) & $812(54.5)$ & $355(52.6)$ & 0.401 \\
\hline Depression & $339(15.7)$ & $217(14.6)$ & $122(18.1)$ & 0.038 \\
\hline $\mathrm{FEV}_{\mathrm{I}} / \mathrm{FVC}$ & $0.64 \pm 0.06$ & $0.64 \pm 0.06$ & $0.64 \pm 0.06$ & 00.181 \\
\hline FVC, L & $3.53 \pm 0.87$ & $3.63 \pm 0.83$ & $3.44 \pm 0.92$ & $<0.001$ \\
\hline FVC, \% predicted & $89.91 \pm 3.38$ & $91.9 \pm 13.26$ & $87.9 \pm 13.5$ & $<0.001$ \\
\hline $\begin{array}{l}\text { FVC, \% predicted } \\
\text { First quartile } \\
\text { Second quartile } \\
\text { Third quartile } \\
\text { Fourth quartile }\end{array}$ & & $\begin{array}{l}325(21.8) \\
346(23.2) \\
404(27.1) \\
414(27.8)\end{array}$ & $\begin{array}{l}216(32.0) \\
195(28.9) \\
137(20.3) \\
127(18.8)\end{array}$ & $<0.001$ \\
\hline $\mathrm{FEV}_{1}, \mathrm{~L}$ & $2.25 \pm 0.61$ & $2.31 \pm 0.61$ & $2.2 \pm 0.61$ & $<0.001$ \\
\hline $\mathrm{FEV}_{1}, \%$ predicted & $78.5 \pm 13.5$ & $79.1 \pm 13.5$ & $77.9 \pm 13.5$ & 0.048 \\
\hline $\begin{array}{l}\mathrm{FEV}_{1} \text {, \% predicted } \\
\text { First quartile } \\
\text { Second quartile } \\
\text { Third quartile } \\
\text { Fourth quartile }\end{array}$ & & $\begin{array}{l}360(24.2) \\
366(24.6) \\
383(25.7) \\
380(25.5)\end{array}$ & $\begin{array}{l}|8|(26.8) \\
175(25.9) \\
158(23.4) \\
161(23.9)\end{array}$ & 0.370 \\
\hline
\end{tabular}

Note: Data are expressed as mean \pm standard deviation or number (\%) as appropriate.

Abbreviations: COPD, chronic obstructive pulmonary disease; MetS, metabolic syndrome; BMI, body mass index; SBP, systolic blood pressure; DBP, diastolic blood pressure; TG, triglyceride; HDL-C, high-density lipoprotein cholesterol; IHD, ischemic heart disease; CHF, congestive heart failure; PVD, peripheral vascular disease; GERD, gastroesophageal reflux disease; $\mathrm{FEV}_{1}$, forced expiratory volume in I second; FVC, forced vital capacity. 
Table 2 Sex Differences in MetS in Early COPD

\begin{tabular}{|c|c|c|c|c|c|c|}
\hline \multirow[t]{2}{*}{ Variable } & \multicolumn{3}{|c|}{ Men $(n=1566)$} & \multicolumn{3}{|c|}{ Women $(n=598)$} \\
\hline & No MetS & MetS & $P$ value & No MetS & MetS & $P$ value \\
\hline Total & II0I (73.4) & $465(26.6)$ & $<0.001$ & $388(64.9)$ & $210(35.1)$ & $<0.001$ \\
\hline Age, years & $64.2 \pm 9.8$ & $65.1 \pm 9.40$ & 0.110 & $62.8 \pm 11.0$ & $68.7 \pm 8.0$ & $<0.001$ \\
\hline BMI, $\mathrm{kg} / \mathrm{m}^{2}$ & $23.0 \pm 2.4$ & $24.9 \pm 2.5$ & $<0.001$ & $22.6 \pm 2.7$ & $25.1 \pm 3.1$ & $<0.001$ \\
\hline $\mathrm{BMI} \geq 25 \mathrm{~kg} / \mathrm{m}^{2}$ & $219(19.9)$ & $225(48.4)$ & $<0.001$ & $64(16.5)$ & $107(51.0)$ & $<0.001$ \\
\hline Participants with a smoking history & $986(89.6)$ & $423(91.0)$ & 0.395 & $69(17.8)$ & $26(12.4)$ & 0.085 \\
\hline Smoking history, pack-years & $27.7 \pm 22.6$ & $29.8 \pm 23.6$ & 0.087 & $2.4 \pm 7.7$ & $1.5 \pm 5.3$ & 0.087 \\
\hline $\mathrm{SBP}, \mathrm{mmHg}$ & $125.0 \pm 16.7$ & $131.1 \pm 14.9$ & $<0.001$ & $121.8 \pm 18.9$ & $132.0 \pm 15.6$ & $<0.001$ \\
\hline $\mathrm{DBP}, \mathrm{mmHg}$ & $77.4 \pm 10.1$ & $79.4 \pm 11.3$ & 0.001 & $74.3 \pm 10.0$ & $76.7 \pm 10.3$ & 0.007 \\
\hline Abdominal circumference, $\mathrm{cm}$ & $83.7 \pm 7.3$ & $90.3 \pm 7.2$ & $<0.001$ & $78.0 \pm 7.8$ & $87.3 \pm 8.4$ & $<0.001$ \\
\hline $\mathrm{TG}, \mathrm{mg} / \mathrm{dL}$ & $131.0 \pm 102.9$ & $222.8 \pm 173.7$ & $<0.001$ & $106.7 \pm 55.3$ & $185.6 \pm 106.1$ & $<0.001$ \\
\hline $\mathrm{HDL}, \mathrm{mg} / \mathrm{dL}$ & $47.6 \pm 10.6$ & $38.9 \pm 8.5$ & $<0.001$ & $52.4 \pm 11.7$ & $43.1 \pm 8.9$ & $<0.001$ \\
\hline Glucose & $98.8 \pm 17.0$ & $114.6 \pm 32.4$ & $<0.001$ & $94.4 \pm 12.4$ & $109.5 \pm 32.1$ & $<0.001$ \\
\hline Diabetes & $316(28.7)$ & $252(54.2)$ & $<0.001$ & $92(23.7)$ & $116(55.2)$ & $<0.001$ \\
\hline Hypertension & $493(44.8)$ & $355(76.3)$ & $<0.001$ & $156(40.2)$ & $174(82.9)$ & $<0.001$ \\
\hline IHD & $94(8.5)$ & $68(14.6)$ & $<0.001$ & $23(5.9)$ & $33(15.7)$ & $<0.001$ \\
\hline $\mathrm{CHF}$ & $55(5.0)$ & $21(4.5)$ & 0.687 & $20(50.2)$ & $24(11.4)$ & 0.005 \\
\hline PVD & $258(23.4)$ & $138(29.7)$ & 0.009 & $98(25.3)$ & $81(38.6)$ & $<0.001$ \\
\hline Arthritis & $104(9.5)$ & $48(10.3)$ & 0.592 & $69(17.8)$ & $58(27.6)$ & 0.005 \\
\hline Osteoporosis & $125(1 \mid .4)$ & $49(10.5)$ & 0.639 & $180(46.4)$ & $110(52.4)$ & 0.162 \\
\hline GERD & $583(53.0)$ & $243(52.3)$ & 0.802 & $229(59.0)$ & $112(53.3)$ & 0.180 \\
\hline Depression & $154(14.0)$ & $67(14.4)$ & 0.827 & $63(16.2)$ & $55(26.2)$ & 0.004 \\
\hline
\end{tabular}

Notes: Data are expressed as mean \pm standard deviation or number (\%) as appropriate.

Abbreviations: MetS, metabolic syndrome; COPD, chronic obstructive pulmonary disease; BMI, body mass index; SBP, systolic blood pressure; DBP, diastolic blood pressure; TG, triglyceride; HDL-C, high-density lipoprotein cholesterol; IHD, ischemic heart disease; CHF, congestive heart failure; PVD, peripheral vascular disease; GERD, gastroesophageal reflux disease.

Table 3 Moderate-to-Severe Exacerbations of COPD and MetS

\begin{tabular}{|c|c|c|c|c|}
\hline \multirow{3}{*}{ Variable } & \multicolumn{4}{|l|}{ Exacerbation } \\
\hline & \multicolumn{2}{|l|}{ Baseline } & \multicolumn{2}{|c|}{ Follow-Up After 5 Years } \\
\hline & $\begin{array}{l}\text { Moderate-to-Severe } \\
\text { Exacerbation }\end{array}$ & $\begin{array}{l}\text { Severe } \\
\text { Exacerbation }\end{array}$ & $\begin{array}{l}\text { Moderate-to-Severe } \\
\text { Exacerbation }\end{array}$ & $\begin{array}{l}\text { Severe } \\
\text { Exacerbation }\end{array}$ \\
\hline Total, $\mathrm{n}$ & $3.5 \pm 4.4$ & $0.1 \pm 0.4$ & $4.7 \pm 5.0$ & $0.1 \pm 0.3$ \\
\hline No MetS & $3.4 \pm 4.5$ & $0.1 \pm 0.4$ & $4.6 \pm 5.1$ & $0.1 \pm 0.3$ \\
\hline MetS & $3.6 \pm 4.2$ & $0.1 \pm 0.3$ & $4.9 \pm 4.6$ & $0.1 \pm 0.02$ \\
\hline$P$ value & $0.4 \mathrm{I}$ & 0.97 & 0.10 & 0.59 \\
\hline \multicolumn{5}{|l|}{ Men } \\
\hline No MetS & $3.3 \pm 4.6$ & $0.1 \pm 0.4$ & $4.5 \pm 5.2$ & $0.1 \pm 0.3$ \\
\hline MetS & $3.2 \pm 4.0$ & $0.1 \pm 0.3$ & $4.5 \pm 4.6$ & $0.1 \pm 0.2$ \\
\hline$P$ value & 0.50 & 0.23 & 0.78 & 0.43 \\
\hline \multicolumn{5}{|l|}{ Women } \\
\hline No MetS & $3.7 \pm 4.3$ & $0.1 \pm 0.3$ & $4.9 \pm 4.9$ & $0.1 \pm 0.2$ \\
\hline MetS & $4.5 \pm 4.6$ & $0.1 \pm 0.5$ & $5.8 \pm 4.4$ & $0.1 \pm 0.2$ \\
\hline$P$ value & 0.03 & 0.14 & 0.02 & 0.85 \\
\hline
\end{tabular}

Note: Data are expressed as mean \pm standard deviation.

Abbreviations: COPD, chronic obstructive pulmonary disease; MetS, metabolic syndrome.

women, moderate-to-severe exacerbations at baseline were year vs. 3.7/year; $\mathrm{P}=0.03$ ) (Table 3). Moreover, during the higher in those with MetS than in those without MetS (4.5/ 5-year follow-up, moderate-to-severe exacerbations were 
significantly higher only in women with MetS than in those without MetS (5.8/year vs. 4.9/year; $\mathrm{P}=0.02$ ) (Table 3).

The crude IRR of moderate-to-severe exacerbations during the 5 years in patients with MetS was significantly higher only in women with MetS than in those without MetS (IRR, $1.19 ; 95 \% \mathrm{CI}, 1.03$ to $1.37 ; \mathrm{P}=0.01$ ) (Figure 1 ). After adjusting for age, sex, and $\mathrm{FEV}_{1} \%$ predicted (Model 1), the IRR was $1.15(95 \% \mathrm{CI}, 1.00$ to $1.34 ; \mathrm{P}=0.04)$ in women, and after adjusting for age, sex, number of pack-years smoked, and $\mathrm{FEV}_{1} \%$ predicted (Model 2), the IRR was 1.17 (95\% CI, 1.01 to $1.36 ; \mathrm{P}=0.03$ ) in women (Figure 1).

\section{COPD-Related Costs and MetS}

COPD-related hospitalization per person-year was higher in MetS (1.7 per person-year vs. 1.2 per person-year; $\mathrm{P}=0.04$ ). Cost for pharmacy use was also higher in MetS (22.7 US dollars [USD] vs. 18.5 USD; $\mathrm{P}=0.02$ ) (Table 4). According to sex, only women showed significantly higher COPDrelated hospitalizations and costs among patients with MetS than among those without MetS (Table 5). The cumulative COPD-related medical costs per person-year were higher in MetS during the 5-year follow-up period (Figure 2). The cumulative COPD-related medical costs per person-year

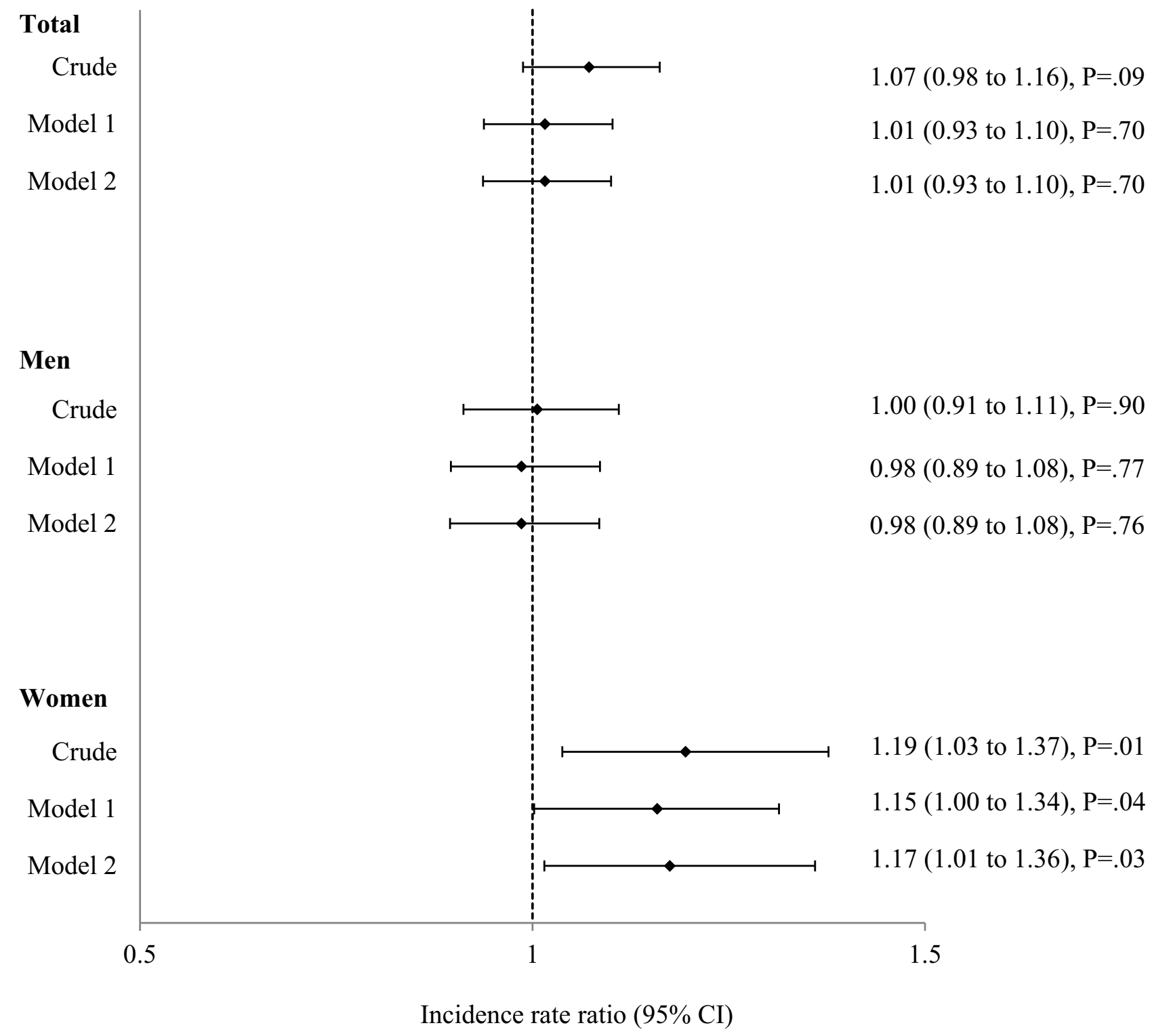

Figure I Incidence rate ratio (IRR) of exacerbations in patients with metabolic syndrome for 5 years. Model I was adjusted for age, sex, and FEV $\%$ predicted. Model 2 was adjusted for age, sex, number of pack-years smoked, and $\mathrm{FEV}_{1} \%$ predicted. Data are presented as IRR $(95 \% \mathrm{Cl})$.

Abbreviations: $\mathrm{Cl}$, confidence interval; $\mathrm{FEV}_{1}$, forced expiratory volume in I second. 
Table 4 Cumulative COPD-Related Health-Care Utilization and Medical Expenses (USD) in All Patients

\begin{tabular}{|c|c|c|c|}
\hline & No MetS & MetS & $P$ value \\
\hline \multicolumn{4}{|l|}{ Hospitalization } \\
\hline $\begin{array}{l}\text { Number per } \\
\text { person-year }\end{array}$ & $1.2 \pm 5.1$ & $1.7 \pm 6.6$ & 0.04 \\
\hline $\begin{array}{l}\text { Cost per person- } \\
\text { year }\end{array}$ & $231.1 \pm 1232.7$ & $293.29 \pm 1157.9$ & 0.26 \\
\hline \multicolumn{4}{|l|}{ Outpatient clinic visits } \\
\hline $\begin{array}{l}\text { Number per } \\
\text { person-year }\end{array}$ & $2.8 \pm 3.9$ & $2.96 \pm 3.6$ & 0.40 \\
\hline $\begin{array}{l}\text { Cost per person- } \\
\text { year }\end{array}$ & $46.2 \pm 119.2$ & $44.19 \pm 69.6$ & 0.61 \\
\hline \multicolumn{4}{|l|}{ Use of pharmacy } \\
\hline $\begin{array}{l}\text { Number per } \\
\text { person-year }\end{array}$ & $2.7 \pm 3.7$ & $2.87 \pm 3.5$ & 0.46 \\
\hline $\begin{array}{l}\text { Cost per person- } \\
\text { year }\end{array}$ & $18.4 \pm 38.1$ & $22.67 \pm 40.6$ & 0.02 \\
\hline
\end{tabular}

Note: Data are expressed as mean \pm standard deviation.

Abbreviations: COPD, chronic obstructive pulmonary disease; USD, US dollars; MetS, metabolic syndrome.

were higher in women with MetS, but not in men with MetS (Figure 2).

\section{Discussion}

COPD and MetS are growing causes of morbidity and mortality worldwide, with a significant impact on public health. To our knowledge, this is the first and largest study to investigate the prevalence of and sex differences in
MetS among patients with early COPD, and the impact of MetS on the frequency of exacerbations and COPDrelated medical costs.

In the present study, the prevalence of MetS among patients with early COPD was $31.2 \%$, and it was significantly higher in women (35.1\%) than in men $(26.7 \%)$. Compared to the age-adjusted overall (27.0\%) and sexspecific prevalence $(27.6 \%$ in women and $25.5 \%$ in men in 2012) of MetS in the Korean adult population, ${ }^{14}$ the prevalence of MetS was higher in patients with early COPD and it occurred more frequently in women. These results are consistent with those of previous pooled studies, ${ }^{9}$ which showed that the mean overall prevalence of MetS among patients with COPD was $34 \%$, with a wide variation according to geographical locations, ranging from $23 \%$ to $37 \%$ in Asia to $58 \%$ in North America, and it was more frequent in women than in men (35\% vs. $24 \%)$. Several studies have investigated the prevalence of MetS according to the GOLD stages, and found it was more frequent in earlier spirometric stages of COPD (GOLD I-II). In a study carried out in Germany, the frequencies of MetS in GOLD stages I-IV were 50\%, 53\%, 37\%, and $44 \%$, respectively. ${ }^{15}$ Minas et al also reported it was more prevalent in GOLD II (66.7\%), whereas its prevalence decreases to about $10 \%$ in GOLD stages III and IV. ${ }^{10}$ The reason why MetS is more prevalent in early GOLD COPD than in severe COPD is unclear, but increased weight loss frequently found in advanced stages might explain this observation. ${ }^{15}$ Moreover, the co-existence of COPD and MetS further increases the risk of CVD, which

Table 5 COPD-Related Health-Care Utilization and Medical Expenses (USD) According to Sex

\begin{tabular}{|c|c|c|c|c|c|c|}
\hline & \multicolumn{3}{|l|}{ Men } & \multicolumn{3}{|l|}{ Women } \\
\hline & No MetS & MetS & $P$ value & No MetS & MetS & $P$ value \\
\hline \multicolumn{7}{|l|}{ Hospitalization } \\
\hline Number per person-year & $1.13 \pm 5.2$ & $1.2 \pm 5.4$ & 0.813 & $1.4 I \pm 4.9$ & $3.0 \pm 8.6$ & 0.01 \\
\hline Cost per person-year & $242.4 \pm 1363.1$ & $208.5 \pm 1369.1$ & 0.569 & $199.2 \pm 1363.1$ & $480.99 \pm 1369.1$ & 0.01 \\
\hline \multicolumn{7}{|l|}{ Outpatient clinic visits } \\
\hline Number per person-year & $2.7 \pm 3.9$ & $2.6 \pm 3.4$ & 0.616 & $2.9 \pm 3.8$ & $3.6 \pm 4.0$ & 0.05 \\
\hline Cost per person-year & $45.6 \pm 1364.1$ & $41.0 \pm 1370.1$ & 0.354 & $47.9 \pm 1364.1$ & $51.0 \pm 1370.1$ & 0.67 \\
\hline \multicolumn{7}{|l|}{ Use of pharmacy } \\
\hline Number per person-year & $2.6 \pm 3.8$ & $2.5 \pm 3.31$ & 0.529 & $2.9 \pm 3.7$ & $3.5 \pm 3.9$ & 0.05 \\
\hline Cost per person-year & $18.0 \pm 1365.1$ & $21.3 \pm 1371.1$ & 0.127 & $19.7 \pm 1365.1$ & $25.6 \pm 1371.1$ & 0.07 \\
\hline
\end{tabular}

Notes: Data are expressed as mean \pm standard deviation.

Abbreviations: COPD, chronic obstructive pulmonary disease; USD, US dollars; MetS, metabolic syndrome. 
A

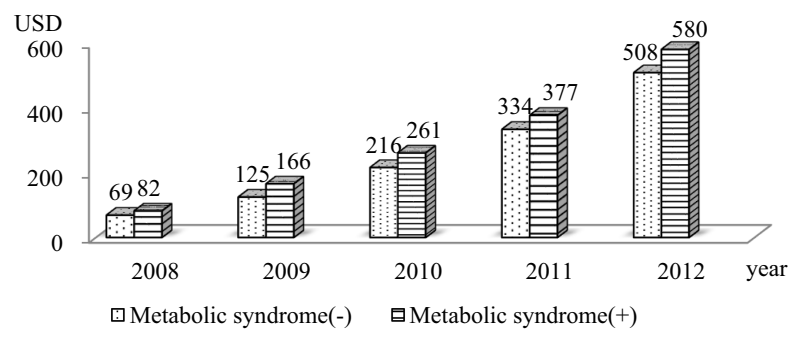

B

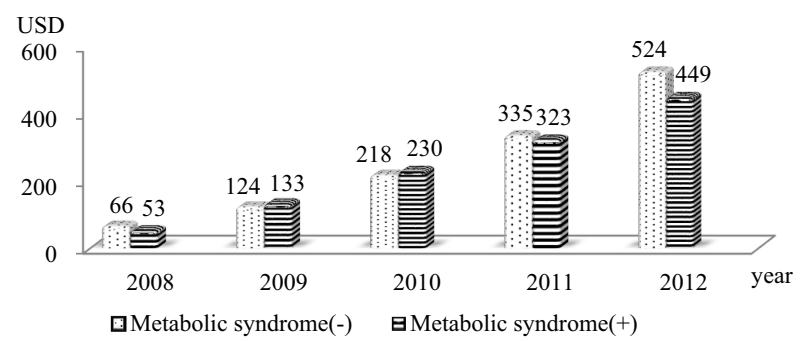

C

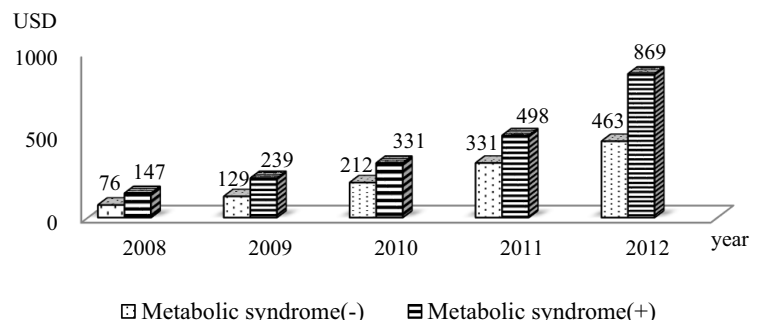

Figure 2 Cumulative medical costs related to chronic obstructive pulmonary disease per person-year according to metabolic syndrome. (A) All patients; (B) Men; and (C) Women.

Abbreviation: USD, US dollars.

may partly explain the increased CVD morbidity and mortality in early COPD. ${ }^{10}$ Therefore, patients with early COPD should be evaluated and treated for MetS appropriately for ensuring a better prognosis especially in women.

In our study, the three most prevalent MetS components in early COPD were hypertension, low HDL-C, and high TG. In early COPD in the Korean population, the glycemia component was the lowest contributor to MetS, whereas the pooled data showed that hypertension, glycemia, and abdominal obesity were the three most prevalent components that defined MetS in patients with COPD. ${ }^{9}$ Abdominal obesity is associated with MetS and restrictive lung function impairment. ${ }^{16}$ In our study, the patients with MetS were distributed lower trends according to the decrement of FVC \% predicted, which were similar to those findings as $\mathrm{FEV}_{1} \%$ predicted.

Previous pooled data ${ }^{10}$ showed that age was not different between patients with and without MetS but another study showed that patients with MetS were younger. ${ }^{10}$ In contrast, this study showed that patients with MetS were older. The number of pack-years smoked was significantly smaller among our patients with MetS, similar to the findings of a previous study. ${ }^{10}$ The BMI was higher among patients with MetS in our study, which was similar to previous results. ${ }^{12}$ Comorbidities based on the ICD-10 codes extracted from the NHI database, such as hypertension, IHD, PVD, and depression, were higher in patients with MetS than in those without MetS. Comorbidities of COPD may be causally related, either as shared risk factors or when one disease increases the risk of other diseases. ${ }^{1}$ The most common risk factor for COPD is smoking, ${ }^{1}$ which is a shared risk factor for systemic inflammation with comorbidities. ${ }^{2,3}$ Smoking induces insulin resistance and can cause MetS. ${ }^{17}$ In this study, women with MetS and COPD were older, had smoked fewer pack-years, and had more frequent comorbidities such as osteoporosis, depression, arthritis, PVD, and arthritis than did men. Factors other than smoking might be related to the development of MetS in women. Systemic inflammation might induce MetS. ${ }^{18}$ We suggest that in the absence of smoking, systemic inflammation from MetS can cause COPD and could increase the risk of exacerbations. ${ }^{19}$ The factors inducing systemic inflammation could be air pollutants, ${ }^{1}$ adipose tissue, ${ }^{10,18}$ etc. The association between MetS and COPD in the absence of smoking is intriguing. Interestingly, recent data indicated elevated insulin levels may induce hypercontractility in airway smooth muscle or potentiate airway hyperresponsiveness to parasympathetic stimulation, which could reduce lung function. ${ }^{20}$ Further investigations are necessary to determine whether improved insulin resistance can reduce lung function decline.

In this study, MetS significantly influenced moderate-to -severe exacerbations of early COPD only in women. This trend has not been seen for severe exacerbations. The IRR for moderate-to-severe exacerbations of MetS over 5 years, evaluated using negative binomial regression, was significantly higher only in women. Similarly, previous studies have shown that MetS impacts the number of all exacerbations of COPD, ${ }^{11,12}$ but the results were obtained from hospitalized patients with COPD, ${ }^{11}$ were preliminary results, ${ }^{12}$ and were based on the analysis of small patient numbers. ${ }^{11,12}$ Thus, the present study is valuable because we investigated the association between MetS and COPD exacerbations by using data from a large national survey database. In the TORCH study, COPD exacerbation rate 
was $25 \%$ higher in women than in men, ${ }^{21}$ and in Turkey, female patients with COPD might be more prone to severe exacerbations, a higher number of hospitalizations, and prolonged hospitalization. ${ }^{22}$ In our study, MetS was higher in women than men, and the frequency of exacerbation was higher in women with MetS than in women without MetS. Limited knowledge is available about the relationship between sex, MetS, and COPD exacerbation. Moreover, we could not ascertain whether sex difference increased exacerbation or whether MetS increased exacerbation in our study. Although this association is still poorly understood, evidence linking MetS and COPD continues to grow, and several potential mechanisms have been proposed, including the effect of adiposity, fat-induced inflammation on the lung, physical inactivity, hypogonadism, and steroid use. ${ }^{20,23}$ On the basis of our significant findings, we could suggest that MetS increased COPD exacerbation in women.

South Korea has a compulsory universal health insurance system that includes medical reimbursement records for the entire Korean population. The NHI reimbursement database provides a unique and advantageous mechanism for evaluating the nationwide magnitude of an illness and consequent health care use. ${ }^{24}$ Thus, we could obtain the exacerbation history and medical costs of COPD. Comorbidities increase the costs for $\mathrm{COPD}^{5}$ and exacerbations. ${ }^{25}$ Our results confirmed that COPD-related hospitalization and pharmacy use were higher in patients with MetS than in those without MetS, and were higher in women than in men. However, MetS did not affect the COPD-related medical utilization and costs in men.

This study had several limitations. First, the cutoff values used for MetS in Korea, such as a waist circumference $\geq 85 \mathrm{~cm}$ for women as defined by the KOSSO,${ }^{13}$ were not based on prospective data. However, when a waist circumference $\geq 80 \mathrm{~cm}$ for women was applied to the Korean population, the prevalence of MetS in women was higher than that in men by approximately 1.5 -fold, ${ }^{26,27}$ and the prevalence of abdominal obesity was higher than $50 \%$ in Korean postmenopausal women. ${ }^{27}$ Thus, we used KOSSO's cutoff value of waist circumference for MetS in Koreans as $\geq 85 \mathrm{~cm}$ for women. ${ }^{13}$ Second, MetS was assessed only at the time of enrollment to the KNHANES. Some patients who were classified as having no MetS in the 2007 KNHANES database could develop MetS during the 5-year follow-up period. Similarly, those with moderate COPD in the 2007 KNHANES database could progress to severe COPD during the 5-year follow-up period.
Nevertheless, we hypothesized and designed the study such that the pulmonary function and MetS components would remain unchanged over 6 years, and thus, the status of MetS and stages of mild-to-moderate COPD at enrollment would remain identical for 5 years. Third, exacerbations were assessed retrospectively by using the ICD-10 codes and prescription history obtained from the NHI database. Thus, we could not count the exact number of exacerbations. Fourth, we included patients with COPD who were never smokers. However, considering the risk factors for COPD other than smoking, this inclusion was justified. Fifth, we exclude asthma subjects upon the questionnaire for self-reported physician-diagnosed asthma conducted by the KNHANES. Usually, studies using national survey depend on the self-reported disease history, which could evoke the major bias.

\section{Conclusion}

The prevalence of MetS in early COPD was not low. Patients with COPD and MetS were older, more obese, more frequently female, and less frequent smokers, and had more comorbidities such as hypertension, PVD, IHD, and depression than did patients with COPD and no MetS. Moreover, they had more severe airflow limitation, as indicated by $\mathrm{FEV}_{1}$ and FVC. MetS significantly impacts the moderate-to-severe exacerbations of early COPD in women. The frequency of hospitalization and pharmacy costs were higher in patients with MetS than in those without MetS, especially in women. COPD with MetS in women might be a different phenotype from smoking-induced COPD. Efforts must be made to identify MetS in patients with COPD, especially women, at the time of diagnosis, treatment, and follow-up. Individualized treatment for patients with COPD and MetS is a challenge. Therefore, further research on the role of MetS in COPD is necessary.

\section{Abbreviations}

$\mathrm{BMI}$, body mass index; $\mathrm{CHF}$, congestive heart failure; CIs, confidence intervals; COPD, chronic obstructive pulmonary disease; CVD, cardiovascular disease; FEV1, forced expiratory volume in 1 second; FVC, forced vital capacity; GERD, gastroesophageal reflux disease; GOLD, Global Initiative for Chronic Obstructive Lung Disease HDL-C, high-density lipoprotein cholesterol; IHD, ischemic heart disease; IRRs, incidence rate ratios; KNHANES, Korean National Health and Nutrition Examination Survey; KOSSO, Korean Society for the Study of Obesity; MetS, 
metabolic syndrome; NHI, National Health Insurance; PVD, peripheral vascular disease; TG, triglyceride.

\section{Ethics Statement}

All KNHANES participants signed an informed consent form. Thus, ethical approval was not required, because our study used data from those surveys retrospectively.

\section{Acknowledgment}

We thank Editage for editing a draft of this manuscript.

\section{Disclosure}

The authors report no conflicts of interest in this work.

\section{References}

1. Global Initiative for Chronic Obstructive Lung Disease (GOLD). Global strategy for the diagnosis, management, and prevention of chronic obstructive pulmonary disease; 2017. Available from: https:// goldcopd.org. Accessed September 2, 2017.

2. Barnes PJ. Chronic obstructive pulmonary disease: effects beyond the lungs. PLoS Med. 2010;7(3):e1000220.

3. Patel AR, Hurst JR. Extrapulmonary comorbidities in chronic obstructive pulmonary disease: state of the art. Expert Rev Respir Med. 2011;5(5):647-662. doi:10.1586/ers.11.62

4. Mannino DM, Thorn D, Swensen A, Holguin F. Prevalence and outcomes of diabetes, hypertension and cardiovascular disease in COPD. Eur Respir J. 2008;32(4):962-969. doi:10.1183/09031936.00012408

5. Mannino DM, Higuchi K, Yu TC, et al. Economic burden of COPD in the presence of comorbidities. Chest. 2015;148(1):138-150. doi:10.1378/chest.14-2434

6. Huber MB, Wacker ME, Vogelmeier CF, Leidl R. Excess costs of comorbidities in chronic obstructive pulmonary disease: a systematic review. PLoS One. 2015;10(4):e0123292. doi:10.1371/journal.pone.0123292

7. Grundy SM, Cleeman JI, Daniels SR, et al. Diagnosis and management of the metabolic syndrome: an American Heart Association/National Heart, Lung, and Blood Institute Scientific Statement. Circulation. 2005;112 (17):2735-2752. doi:10.1161/CIRCULATIONAHA.105.169404

8. Aguilar M, Bhuket T, Torres S, Liu B, Wong RJ. Prevalence of the metabolic syndrome in the United States, 2003-2012. JAMA. 2015;313(19):1973-1974. doi:10.1001/jama.2015.4260

9. Cebron Lipovec N, Beijers RJ, van den Borst B, Doehner W, Lainscak M, Schols AM. The prevalence of metabolic syndrome in chronic obstructive pulmonary disease: a systematic review. COPD. 2016;13(3):399-406.

10. Minas M, Kostikas K, Papaioannou AI, et al. The association of metabolic syndrome with adipose tissue hormones and insulin resistance in patients with COPD without co-morbidities. COPD. 2011;8 (6):414-420. doi:10.3109/15412555.2011.619600

11. Mekov E, Slavova Y, Tsakova A, et al. Metabolic syndrome in hospitalized patients with chronic obstructive pulmonary disease. Peer J. 2015;3:e1068. doi:10.7717/peerj.1068
12. Kupeli E, Ulubay G, Ulasli SS, Sahin T, Erayman Z, Gursoy A. Metabolic syndrome is associated with increased risk of acute exacerbation of COPD: a preliminary study. Endocrine. 2010;38(1):76-82. doi:10.1007/s12020-010-9351-3

13. Lee S, Park HS, Kim SM, et al. Cut-off points of waist circumference for defining abdominal obesity in the Korean population. Korean J Obes. 2006;15(1):1-9.

14. Tran BT, Jeong BY, Oh JK. The prevalence trend of metabolic syndrome and its components and risk factors in Korean adults: results from the Korean National Health and Nutrition Examination Survey 2008-2013. BMC Public Health. 2017;17(1):71. doi:10.1186/ s12889-016-3936-6

15. Watz H, Waschki B, Kirsten A, et al. The metabolic syndrome in patients with chronic bronchitis and COPD: frequency and associated consequences for systemic inflammation and physical inactivity. Chest. 2009;136(4):1039-1046. doi:10.1378/chest.09-0393

16. Leone N, Courbon D, Thomas F, et al. Lung function impairment and metabolic syndrome: the critical role of abdominal obesity. Am $J$ Respir Crit Care Med. 2009;179(6):509-516. doi:10.1164/ rccm.200807-1195OC

17. Piazzolla G, Castrovilli A, Liotino V, et al. Metabolic syndrome and Chronic Obstructive Pulmonary Disease (COPD): the interplay among smoking, insulin resistance and vitamin D. PLoS One. 2017;12(10):e0186708. doi:10.1371/journal.pone.0186708

18. Clini E, Crisafulli E, Radaeli A, Malerba M. COPD and the metabolic syndrome: an intriguing association. Intern Emerg Med. 2013;8 (4):283-289. doi:10.1007/s11739-011-0700-x

19. Groenewegen KH, Postma DS, Hop WC, Wielders PL, Schlosser NJ, Wouters EF. Increased systemic inflammation is a risk factor for COPD exacerbations. Chest. 2008;133(2):350-357. doi:10.1378/ chest.07-1342

20. Baffi CW, Wood L, Winnica D, et al. Metabolic Syndrome and the Lung. Chest. 2016;149(6):1525-1534. doi:10.1016/j.chest.2015.12.034

21. Celli B, Vestbo J, Jenkins CR, et al. Sex differences in mortality and clinical expressions of patients with chronic obstructive pulmonary disease. The TORCH experience. Am J Respir Crit Care Med. 2011;183(3):317-322. doi:10.1164/rccm.201004-0665OC

22. Kilic H, Kokturk N, Sari G, Cakir M. Do females behave differently in COPD exacerbation? Int J Chron Obstruct Pulmon Dis. 2015;10:823-830. doi:10.2147/COPD.S78952

23. Wells C, Baker E. Metabolic syndrome and European Respiratory Monograph 59: COPD and Comorbidity. Eur Res Monograph. 2013;59:117-134.

24. National Health Insurance Service. Available from: http://www.nhis.or. $\mathrm{kr} / \mathrm{static} / \mathrm{html} / \mathrm{wbd} / \mathrm{g} / \mathrm{a} / \mathrm{wbdga0101}$.html. Accessed September 2, 2017.

25. Terzano C, Colamesta V, Unim B, et al. Chronic obstructive pulmonary disease (COPD) exacerbation: impact of comorbidities on length and costs during hospitalization. Eur Rev Med Pharmacol Sci. 2017;21(16):3680-3689.

26. Hong AR, Lim S. Clinical characteristics of metabolic syndrome in Korea, and its comparison with other Asian countries. $J$ Diabetes Investig. 2015;6(5):508-515. doi:10.1111/jdi.2015.6.issue-5

27. Lim S, Shin H, Song JH, et al. Increasing prevalence of metabolic syndrome in Korea: the Korean National Health and Nutrition Examination Survey for 1998-2007. Diabetes Care. 2011;34 (6):1323-1328. doi:10.2337/dc10-2109 


\section{Publish your work in this journal}

The International Journal of COPD is an international, peer-reviewed journal of therapeutics and pharmacology focusing on concise rapid reporting of clinical studies and reviews in COPD. Special focus is given to the pathophysiological processes underlying the disease, intervention programs, patient focused education, and self management protocols. This journal is indexed on PubMed Central, MedLine and CAS. The manuscript management system is completely online and includes a very quick and fair peer-review system, which is all easy to use. Visit http://www.dovepress.com/testimonials.php to read real quotes from published authors. 